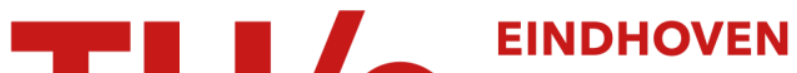 \\ UNIVERSITY OF \\ TECHNOLOGY
}

\section{Sensing muscle activities with body-worn sensors}

\author{
Citation for published version (APA): \\ Amft, O. D., Junker, H., Lukowicz, P., Tröster, G., \& Schuster, C. (2006). Sensing muscle activities with body- \\ worn sensors. In Proceedings wearable and implantable Body Sensor Networks (BSN) 2006, International \\ workshop, Cambridge, 3-5 April 2006 [1612915-141] Institute of Electrical and Electronics Engineers. \\ https://doi.org/10.1109/BSN.2006.48
}

DOI:

10.1109/BSN.2006.48

Document status and date:

Published: 01/01/2006

\section{Document Version:}

Publisher's PDF, also known as Version of Record (includes final page, issue and volume numbers)

\section{Please check the document version of this publication:}

- A submitted manuscript is the version of the article upon submission and before peer-review. There can be important differences between the submitted version and the official published version of record. People interested in the research are advised to contact the author for the final version of the publication, or visit the $\mathrm{DOI}$ to the publisher's website.

- The final author version and the galley proof are versions of the publication after peer review.

- The final published version features the final layout of the paper including the volume, issue and page numbers.

Link to publication

\section{General rights}

Copyright and moral rights for the publications made accessible in the public portal are retained by the authors and/or other copyright owners and it is a condition of accessing publications that users recognise and abide by the legal requirements associated with these rights.

- Users may download and print one copy of any publication from the public portal for the purpose of private study or research.

- You may not further distribute the material or use it for any profit-making activity or commercial gain

- You may freely distribute the URL identifying the publication in the public portal.

If the publication is distributed under the terms of Article 25fa of the Dutch Copyright Act, indicated by the "Taverne" license above, please follow below link for the End User Agreement:

www.tue.nl/taverne

Take down policy

If you believe that this document breaches copyright please contact us at:

openaccess@tue.nl

providing details and we will investigate your claim. 


\title{
Sensing Muscle Activities with Body-Worn Sensors
}

\author{
Oliver Amft ${ }^{1}$, Holger Junker ${ }^{2}$, Paul Lukowicz ${ }^{2}$, Gerhard Tröster ${ }^{1}$, Corina Schuster ${ }^{3}$ \\ ${ }^{1}$ Wearable Computing Lab, ETH Zurich, Switzerland \\ ${ }^{2}$ Institute for Computer Systems and Networks, UMIT, Hall i. Tirol, Austria \\ ${ }^{3}$ Reha Rheinfelden, Switzerland
}

\begin{abstract}
We demonstrate that simple, unobtrusive sensors attached to the lower arm can be used to capture muscle activations during specific hand and arm activities such as grasping. Specifically, we investigate the use of force sensitive resistors and fabric stretch sensors, that can both be easily integrated into clothing. We use the above sensors to detect the contractions of arm muscles. We present and compare the signals that both sensors produce for a set of typical hand actions. We finally argue that they can provide important information for activity recognition.
\end{abstract}

\section{Introduction}

Many human activities involve arm actions. Key characteristics of such actions are arm motions, hand activities and the force applied to the object the user is interacting with. As an example, consider taking a sip from a small glass of water as opposed to drinking from large beer mug. The arm motions are virtually the same. The difference lies in the way the object is grasped (slightly bent fingers around the glass vs. fully closed hand on the mug handle) and the weight of the object itself.

While movements of the lower arm can be sensed unobtrusively, e.g using inertial or bending sensors integrated into the garment, capturing hand actions typically requires the use of instrumented gloves which can be cumbersome to wear. Alternatively the electrical activity of muscle contractions can be sensed (see related work). However, this requires complex signal processing schemes and the use of electrodes, that are difficult to handle. As a consequence, most wearable activity recognition work is based on arm motion analysis only, ignoring potentially important information contained in hand motions.

In this paper, we evaluate the use of two sensor types mounted on the lower arm to detect arm and hand activities. The work is based on two well known facts: (1) hand motions are controlled by muscles of the lower arm and (2) muscle contractions are accompanied by a change of muscle circumference [2]. From the above considerations, we investigate the use of force sensitive resistors (FSRs) and fabric stretch sensors unobtrusively mounted on the lower arm to capture muscle volume changes related to hand and arm activities.

This work describes the results of initial experiments conducted to determine if the above approach produces meaningful signals for relevant activities and which of the two sensors is more suitable for the task. However, the work does not deal with automatic recognition of different activities from the sensor signals, which is subject of ongoing and future work.

In Section 2 and 3 we discuss our sensing approach and briefly explain our experimental setup, respectively. Section 4 presents the results of our evaluation. We conclude our work by discussing the practical applications of the sensing approach in context-aware applications and medical practice in Section 5.

\subsection{Related Work}

Various gloves have been developed to directly acquire actions of the hands, e.g. as maintenance computer input [3]. While such instrumented gloves allow for a very fine-grained finger activity monitoring, their use is obviously restricted to applications, where they are no burden to the user and where they do not interfere with the user's activity.

Systems have been developed that use muscle contraction e.g. to control computer interfaces or to monitor rehabilitation improvements in stroke patients. To date, the use of electro-myographic (EMG) electrodes are the primary choice for such applications, e.g. for flight control [5] or treatment feedback for hemiplegic patients [1].

However the surface electrodes used to capture Electromyographic signals require very good contact with the human skin to keep artifacts low. Ideally, the electrodes provide a moisturising gel and are attached to cleaned, fat-free and hairless skin. The acquisition of muscle contractions using non-gel electrodes in mobile systems has been shown mostly for Electrocardiogram (ECG) applications, e.g. [4], however with varying accuracy. 


\section{Sensing Approach}

For the detection of lower arm muscle activation we propose to use simple, low cost sensors to meet the following requirements: unobtrusive integration into garments, small power consumption for extended lifetime and simple interfacing. We investigate force sensitive resistors (FSRs) and Carbon-loaded rubber fabrics to detect the muscle activation by sensing its mechanical deformation.

\subsection{Sensing Devices}

Force Sensitive Resistor: A Force sensitive resistor is a polymer thick film device which changes its resistance according to the force applied to its active surface. The resistance is inversely proportional to the applied load. If unloaded and unbent, the stand-off resistance of the FSR is typically very high (larger than $1 \mathrm{M} \Omega$ ) and decreases to several $\mathrm{k} \Omega$. Force sensitive resistors require only a simple interface, consume little power, are unobtrusive and lightweight. Thus, they are ideal for wearable applications.

Fabric stretch sensor: A conductive carbon-loaded rubber can be vulcanised on an elastic textile to yield a conductive fabric. The electrical resistance of this fabric depends on its stretch. Thus it can be used as a strain sensor. When elongated, the resistance increases. However the resistance is highly non-linear in its reaction to strain and exhibits hysteresis which can be problematic in some applications. Such carbon-loaded rubber fabrics are lightweight and can easily be integrated into a garment. In the light of wearable computing, attempts have already been made to use such sensors to detect body postures and arm gestures, e.g. [3].

\subsection{Physiological Aspects}

Every skeletal muscle consists of three parts: a muscle belly and two tendon ends. The muscle contraction is caused by an activation potential transferred via nervemuscle connections. This property is used by EMG to derive a voltage measured with electrodes.

The muscle belly contains multiple muscle patches. Each muscle patch consists of muscle fibres build from filaments. During a muscle contraction the filaments in every muscle fibre slide against each other [2]. The contraction can be perceived visually as an increase of the muscle belly circumference due to the filament slide. This fact is exploited in our sensing approach.

While EMG surface electrodes are typically attached to the ends of the muscle belly, we intend to place our sensors directly on the belly centre, where the deformation is expected to be largest.

\section{Experiments}

We have found that during isometric activity (strain against resistance) of the lower arm and hand grasp activity mainly two muscles of the lower arm are active: M. brachioradialis and M. extensor carpi radialis longus. From this observation we derived 4 distinctive actions of the lower right arm and the hand that activate those muscles.

Protocol: The actions were executed by test subjects sitting on a chair. During all actions, the activations of relevant muscles were independently recorded using two sensor setups and two EMG channels sampled at $2 \mathrm{kHz}$ for comparison. For each action, 20 repetitions were recorded per sensor setup from 2 subjects. In order to verify our sensing approach, we examined the main functions of the selected muscles in isolation (Action 1 and 2), while action 3 and 4 consist of functional activities. The following list details the experimental procedure:

Action 1: Upward movement of lower arm against resistance. The subject was sitting on the chair with the elbow joint initially lying on the arm-rest. The lower arm was oriented in neutral position between pronation and supination with an initial flexion of $90^{\circ}$ to the upper arm. In this position the maximum strength of $\mathrm{M}$. brachioradialis can be obtained. The arbitrary isometric contraction against a distal resistance at the lower arm was evaluated.

Action 2: Outward bending of hand. The initial position was the same as in Action 1. The evaluated action consists of a dorsal extension combined with slight radial abduction of the hand.

Action 3: Opening and closing hand (grasping motion). The initial position was the same as in Action 1. The hand was closed and opened to imitate a grasping activity.

Action 4: Lifting of heavy object with right arm. The subject was sitting on the chair. The lifting object is grasped with the hand and lifted from a table in front of the subject.

The following sensor setup reflects the required interface and attachment for each sensor type:

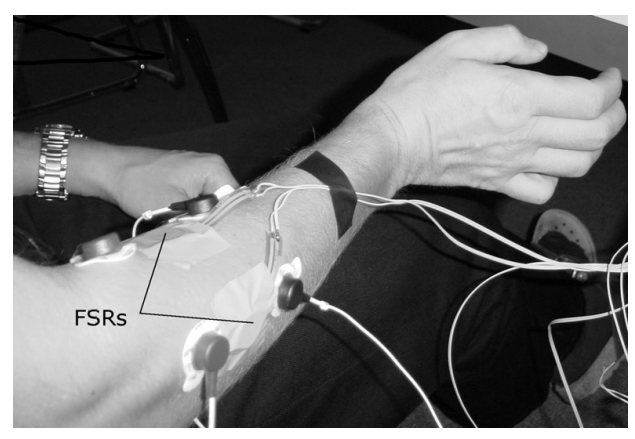

Figure 1. Placement of FSRs on the lower arm. (Larger white disks are the EMG electrodes.)

Setup 1: In a first setup, we attach two force sensitive resistors to the lower arm onto the belly centres of the two 
muscles under consideration using (cf. Fig. 1). We then interface the two FSRs to a simple circuitry (cf. Fig. 3(a)). We use a signal processor to convert the voltage above the $100 \mathrm{k} \Omega$ resistor (cf. Fig. 3(a)) into 8 bit values using a sampling frequency of $10 \mathrm{~Hz}$.

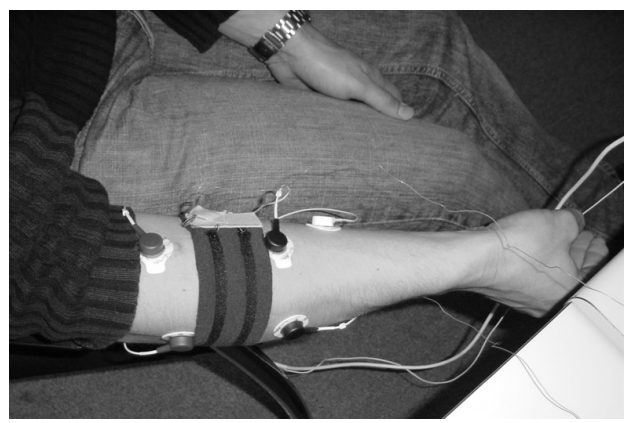

Figure 2. Placement of fabric stretch sensor. (Larger white disks are the EMG electrodes.)

Setup 2: In the second setup, we wrap the conductive fabric material around the lower arm covering the belly centres of the two muscles under consideration. The bandage is slightly stretched when the lower arm is relaxed and fixed using velcro. In order to measure the changing resistance of the fabric stretch sensor, we use a Wheatstone bridge depicted in figure $3(\mathrm{~b})$.

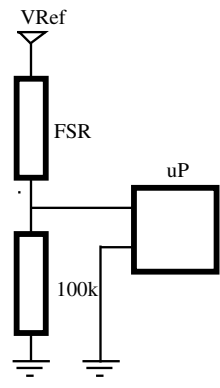

(a) FSR interface.

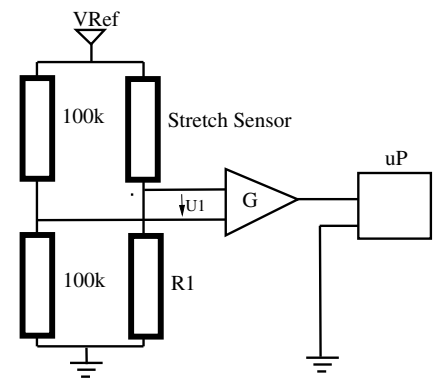

(b) Stretch Sensor interface.
Figure 3. Interface circuitry.

\section{Results}

\subsection{Force Sensitive Resistors}

Figure 4 depicts the signals of the FSRs during execution of the four distinctive actions described in the previous section. The horizontal lines in the graph highlight signal sections where the corresponding EMG amplitude exceeds a specific threshold value, indicating muscle activity. A comparison between those lines and the FSR signals in
Table 1. Number of muscle activations derived from the sensors during execution.

\begin{tabular}{|c|c|c|c|c|}
\hline \multirow{2}{*}{ Action } & \multirow{2}{*}{ Total } & \multicolumn{2}{|c|}{ FSRs } & Fabric \\
& events & rad. longus & $\begin{array}{c}\text { M. brachio- } \\
\text { radialis }\end{array}$ & \\
\hline \hline 1 & 40 & 0 & 40 & 40 \\
\hline 2 & 40 & 39 & 0 & 40 \\
\hline 3 & 40 & 40 & 0 & 40 \\
\hline 4 & 40 & 40 & 40 & 39 \\
\hline
\end{tabular}

Figure 4 shows a clear correlation indicating that muscle activity monitoring is feasible using FSRs. Furthermore, we see that for action 2 and 3, only the FSR at the M. extensor carpi radialis longus is "triggered", whereas for action 1 only the FSR mounted on the M. brachioradialis exhibits activity. Action 4 triggers both sensors. We have used the activity indication derived from the EMG amplitude to evaluate whether the FSRs have detected the muscle activations properly using a simple threshold detector on the FSR signal amplitudes (cf. Tab. 1). The results indicate that the FSRs can be used to monitor individual muscles.

Action 1 (Pull up arm)

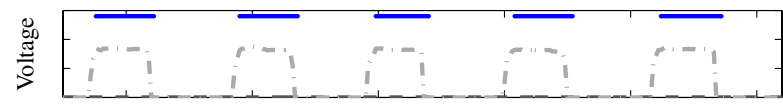

Action 2 (Bend hand)

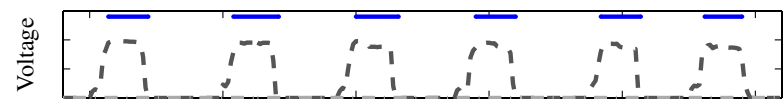

Action 3 (Grasp)

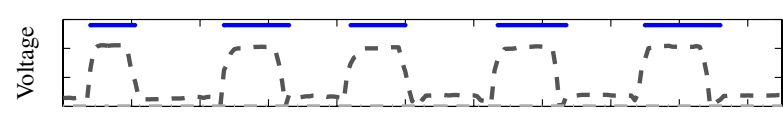

Action 4 (Lift chair)

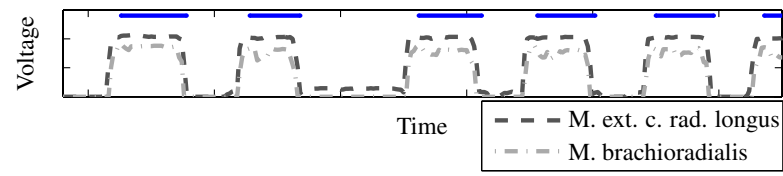

Figure 4. Signals of the FSRs sensors.

\subsection{Fabric Stretch Sensor}

For the fabric stretch sensor, we can make the following observations (cf. Fig.5): For any of the four actions, the stretch sensor signal changes when the action is executed. These changes indicate a change in the circumference of the lower arm. Note that signal amplitudes cannot be directly compared due to the different gain settings of the differential amplifier for each action. 
While actions 1, 3 and 4 lead to an increase, action 2 causes a decrease in the circumference of the lower arm during hand opening. This decrease is due to the fact that while the outer side muscle (M. extensor carpi radialis longus) contracts - leading to a larger circumference - the inner side muscles (M. palmaris longus, M. flexor carpi radialis et ulnaris) are stretched leading to a smaller circumference. The amount of decrease is larger than the amount of increase due to the larger size of the inner side muscles, thus leading to an overall decrease in lower arm circumference.

Action 1 (Pull up arm)
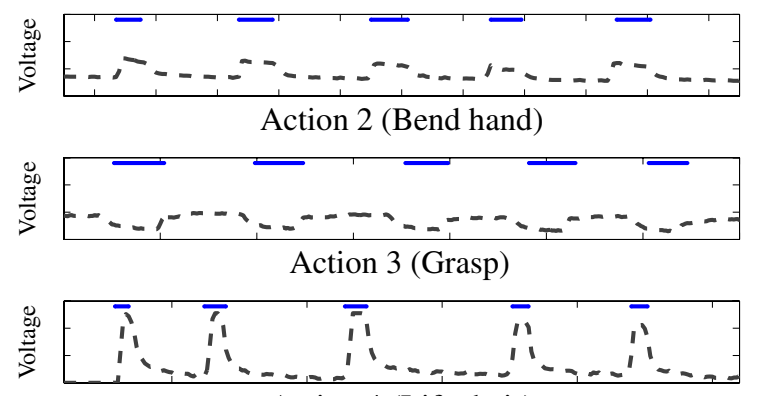

Action 4 (Lift chair)

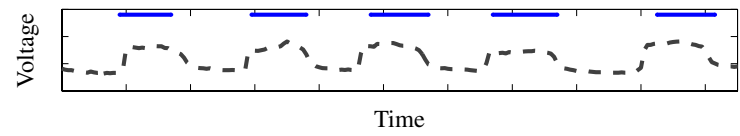

Figure 5. Signals of the fabric stretch sensor.

\section{Discussion}

The results indicate that the proposed mechanical sensors provide alternative methods to detect muscle activities. We have shown that such activities can be acquired from the various independent muscles at the lower arm.

Furthermore, the results indicate that the FSR sensing concept is more applicable to the monitoring of individual muscles, similar to EMG sensing while the fabric stretch sensor cannot be used for monitoring individual muscles. In addition, the use of the fabric stretch sensor is limited due to the fact that the sensor exhibits a strong hysteresis.

We note that the arbitrary lifting of a heavy object will not only activate the selected near-surface muscles, but also muscles at deeper body layers. Hence the observed activity at the selected muscles may not be the sole activation and deeper layer muscles may support the measured signal. Generally the isolated activation of muscles in deeper body layers cannot be monitored by a mechanical sensing approach, however the same is generally valid for surface EMG. Since muscle properties depend on usage, age and sex the results must be validated in larger studies.

The evaluated movements reflect typical activities of daily living, e.g. to hold a bottle of water. The training of such movements are an important part in the rehabilitation of patients after central nervous disorders, e.g. stroke. The integration of simple objective muscle activation measurements into the rehabilitation process will provide a new way of documenting changes and trend analysis. Moreover, the correct muscle activation can be monitored during training sessions. While classic surface EMG is usually too complicated and obtrusive due to the electrode attachment, our sensing approaches can be a potential alternative. However, it needs to be validated with patients.

\section{Outlook}

The experimental results clearly indicate that the investigated sensing technologies are suited for muscle activity detection. However, a number of issues have to be addressed in the future. Among others, these include: measurement inaccuracies due to varying sensor attachment, measurement artifacts occurring while lower arm is bent towards upper arm, measurement artifacts depending on muscle properties (size of lower arm muscles are person-specific) and exploitation of technologies for real, wearable applications. Furthermore, the derivation of physical effort behind a specific activity is of crucial interests.

\section{Acknowledgment}

This work was partly supported by the Swiss State Secretariat for Education and Research (BBW).

\section{References}

[1] O. Armagan et al. Electromyographic biofeedback in the treatment of the hemiplegic hand: A placebocontrolled study. American Journal of Physical Medicine \& Rehabilitation, 82(11):856-861, November 2003.

[2] W. Linke and G. Pfitzer. Physiologie des Menschen, chapter 6, page 117ff. Springer Verlag Berlin, Heidelberg, 2005.

[3] F. Lorussi et al. Strain sensing fabric for hand posture and gesture monitoring. IEEE Transactions on Information Technology in BioMedicine, 9(3):372-381, September 2005.

[4] J. Mühlsteff et al. Wearable approach for continuous ECG and activity patient-monitoring. In Proc. of the IEEE Conference of Engineering in Medicine and Biology, pages 2184-2187, Sep 2004.

[5] K. R. Wheeler and C. C. Jorgensen. Gestures as input: Neuroelectric joysticks and keyboards. IEEE Pervasive Computing, 2(2):56 - 61, April 2003. 